\title{
Histochemical Studies on the "Chiai" Muscle (Red Muscle) of the Fish
}

\section{The Intracellular Localization of Adenosine Triphosphatase \\ Activities and Glycogens, with Special Reference to \\ the Function of the Fish}

By

\section{Chikataro Togari}

Department of Anatomy, Nagoya University Medical School, Nagoya

\section{Heima Uematsu}

Department of Anatomy, Nagoya City University Medical School, Nagoya with six figures

\section{Introduction}

In recent years the role of adenosine triphosphate has been postulated and examined in muscle contraction (L o h m a n n, '34; Sze n tG y ö rg y i, '51). The enzyme directly concerned is usually ascribed to adenosine triphosphatase (ATPase), although the identity of this enzyme with myosin remains still problematical (E $\mathrm{ng}$ e l ha $\mathrm{rdt}$ and Li ubimova, '39; Baile y, ' 42 ; Need ha m, ' 42 ; Price and Cori, '46; Polis and Meyerhof, '46). Recently it has become evident that there is at least one other ATPase differing from myosin-ATPase in muscle in various respects.

On the other hand, the recent knowledge of enzymatic chemistry has made clear that the mitochondria are associated with the "organized complex" enzyme system, in which phosphorylating oxidation is obligatorily linked with phosphorylation of adenosine diphosphate, and furthermore dephosphorylation of adenosine triphosphate is a necessary condition for various cellular function (as muscle contraction) and for the continuation of glycolytic and oxidative metabolisms. More recently, Novikoff et al ('53) reported the fact that the mitochondrial fraction from rat liver homogenate 
possesses high specific activity for ATPase. In view of these, the results of a study on the mitochondria contained in the "Chiai" muscle fiber of several fishes (U e mat $\mathrm{s} \mathrm{u}$, '54) prompted us to study further the functional significance of this muscle. An attempt was made (1) to follow the histochemical distribution pattern of ATPase in the "Chiai" muscle fiber in comparison with the lateral muscle (white muscle) fiber, (2) to determine how in the "Chiai" muscle fiber, the intracellular localization of ATPase coincides with the sites of mitochondria and (3) to speculate on the significance of the presence of abundant glycogen in relation to ATPase.

\section{Materials and Methods}

Materials consisted of the following three species of mature teleosts: Carassius auratus (LINNÉ), Cyprinus carpio (LINNE) and Oncorhyncus masou (BREVOOT). They were collected from rivers in the vicinity of Nagoya and killed by bleeding from the heart.

1. Adenosine triphosphatase: Tissue materials were removed as quickly as possible and immediately frozen on the stage of a freezing microtome with half-saturated sodium acetate solution. Sections of 15-20 $\mu$ thick were cut and dropped directly from the microtome knife into the incubating medium devised by $M$ a e $\mathrm{n} g \mathrm{w}$ y $\mathrm{n}-\mathrm{D}$ a v i e s et al ('52) and the medium by $\mathrm{Padyku} \mathrm{la}$ and $\mathrm{Herman} \mathrm{('55).}$ The following Maeng y n-Davies' medium modified by the authors was chiefly used: Glycine buffer, $\mathrm{pH} 7.45$, containing $0.1 \mathrm{M}$ glycine and $0.4 \mathrm{M} \mathrm{KCl}$ in saturated sodium acetate, $2.0 \mathrm{~mL}$; saturated sodium acetate, $2.0 \mathrm{~mL} ; 036 \mathrm{M} \mathrm{CaCl}_{2}, 0.8 \mathrm{~mL} ; 0.1 \mathrm{M} \mathrm{KOH}, 0.2 \mathrm{~mL}$; $0.04 \mathrm{M}$ ATP, $1.0 \mathrm{~mL}$; distilled water, $2.0 \mathrm{~mL}$. This medium was left in a $37^{\circ} \mathrm{C}$. oven for one hour and then filtered at the same temperature. The $\mathrm{pH}$ was adjusted at $8.25-8.30$ with a glass electrode system. All measurements of $\mathrm{pH}$ were made at $20^{\circ} \mathrm{C}$. At the termination of each incubation the sections were washed three times in $75 \%$ alcohol containing $1 \%$ calcium chloride and then mounted on glass slides filmed by egg-albumen. The slides were dried perfectly at $37^{\circ} \mathrm{C}$. on the warming plate. Enzymatic activity was then visualized by the cobalt sulfide technic. True ATPase activity was confirmed by incorporation of activator (L-cystein and BAL) and sulfhydryl inhibitor (p-chloromercuribenzoic acid) into the incubating medium of $\mathrm{P}$ a d ykula. Recently, it has been found that high concentrations of glycine and other amino acid can inhibit alkaline phosphatase (Bo- 
dansky, '46). Accordingly, the incubating medium devised by $\mathrm{M}$ a e $\mathrm{ng}$ y $\mathrm{n}-\mathrm{D}$ avies et al ('52), and modified by the authors were chiefly used in this study.

Glycogen: Fresh materials were fixed in $96 \%$ alcohol for 24 hours or in Carnoy's fluid for one hour, and embedded in paraffin in the usual manner. They were cut at $5 \mu$ in thickness and stained with Best carmine method and Hotchkiss-Lillie (PAS) method for polysaccharides. Before the staining, some sections were exposed, as a control, to fresh saliva at $37^{\circ} \mathrm{C}$. for one hour.

\section{Observations and Results}

\section{Distribution of Mitochondria}

\section{"Chiai" Muscle Fibers}

In a previous paper (U e mat $\mathrm{s} u$, '54) the junior author reported that the mitochondria of the "Chiai" muscle fiber are found in large amounts and vary in form as filaments, rods, short rods and granules. This is especially marked in the sarcoplasmic mantle found between the muscle column field and sarcolemm, and vice versa in the intercolumnar sarcoplasm (fig. 1), The mitochondria are found very abundantly in several fishes (Carassius auratus and others) which have sarcoplasm-rich fibers, but the amount depends to some degree upon the type of fiber even in the same species. The serpentine type contains much and the reticular, garland-like and annular type relatively little.

Besides the mitochondria there are found other granules of special type in the "Chiai" muscle fiber, which appear in general bilaterally in contact with both margins of the muscle column at the level of the anisotropic bands. Based upon their restricted situation, the junior author has called these granules "clumnosomes" and considered them as being included in the category of mitochondria (fig. 1).

\section{Lateral Muscle Fibers}

Lateral muscle fibers obviously differ in appearance from "Chiai" muscle fibers and its sarcoplasmic mantle is seen with difficulty. Mitochondria are found in the narrow area of sarcoplasm and very small in amount. Longitudinal sections show that they appear as granules or short rods and arranged in longitudinal rows between the muscle columns or just beneath the sarcolemm. No granules comparable with the columnosomes can be found in this muscle. 


\section{Distribution of Adenosine Triphosphatase \\ "Chiai" Muscle Fibers}

The "Chiai" muscle fiber presents precisely a reproducible feature of the activity of ATPase from the mitochondrial distribution pattern. The detailed pattern is as follows: The "Chiai" muscle fiber indicates in general a much higher activity when compared with the lateral muscle fiber. The enzyme attacking ATP at $\mathrm{pH}$ 8.25 indicates much higher activity in the sarcoplasmic mantle after two or three hours' incubation, but far less in the intercolumnar sarcoplasm. The localization of ATPase activity coincides with the sites of columnosomes as well as mitochondria. After 12 hours' incubation, the sarcoplasmic mantle appears black of a far greater intensity than the intercolumnar sarcoplasm. In cross section, ATPase activity is shown as a black circuling zone around the muscle column field (figs. 2 and 3), while in longitudinal section it appears as paired black fringes immediately lateral to both margins of the muscle column field (fig. 4). It is of special interest that a much more increased ATPase activity occurs in accordance with the situation of the junior author's columnosomes. Nuclei appear as a dark structure with perfectly continuous black membrane in accordance with their activity at $\mathrm{pH} 8.25$ after short incubation, but after longer incubation they are completely masked by the dark zone of ATPase activity in the sarcoplasmic mantle.

\section{Lateral Muscle Fibers}

The distribution pattern of ATPase activity in the lateral muscle fiber presents some features different from that of the "Chiai" muscle fiber. It exhibits a minimum activity in the mitochondrial area of the peripheral sarcoplasm, regardless of the length of incubation period or the species of fishes (fig. 5).

\section{Distribution of Glycogen}

\section{"Chiai" Muscle Fibers}

The distribution pattern of glycogen in the "Chiai" muscle fiber, likewise, reveals some marked differences from that of the lateral one. The glycogen is generally in the form of granules and small lumps; it is always abundant in the sarcoplasmic mantle in all species examined, but far less so in the intercolumnar sarcoplasm. In cross section it sometimes appears reticulated or packed in the sarcoplasmic mantle, while it often in the form of dots in the intercolumnar sarcoplasm (fig. 6). In longitudinal section, glycogen 
appears aligned in longitudinal rows at the level of the anisotropic bands in the intercolumnar sarcoplasm.

\section{Lateral Muscle Fibers}

Glycogen of the lateral muscle fiber differs markedly in distribution pattern from that of the "Chiai" muscle fiber. It is far less in amount than in the latter, and is exclusively found in the intercolumnar sarcoplasm.

\section{Discussion}

Although a number of papers have appeared in Japan on the biochemical data of the "Chiai" muscle fiber, very few have dwelt on the morphological functional viewpoint. In a previous paper (U e mats $u, ' 54$ ), the junior author pointed out the importance of the relationship existing between the mitochondria and enzyme in the same muscle fiber and reviewed numerous references on this problem. In the present paper, the following categories will be discussed in views of the evidence presented in the most recent reports.

\section{Localization of ATPase}

Biochemical studies of the intracellular localization of ATPase in skeletal muscle have give ample evidence for its presence in the myofibrils. It has already been reported by many investigators that ATPase activity in the muscle is closely associated with myosin (Eng e l h ardt and Li u bi mova, '39; N e ed h a m, '42; B a ile y, '42; S i n ger and B a r r o n, '44; Sze n t-G y ör g y i, '51; Ge r g e$\mathrm{l} \mathrm{y}, ' 53$; Gree $\mathrm{n}$ and Mom maerts, '53; Mo m maerts and Gree $\mathrm{n}$, '54). On the other hand, Price and Cori ('46) reported that ATPase is separated from myosin. Gilmour ('48) has reported that in the insect muscle, ATPase is detached much more easily from myosin. Recent reports indicate that ATPase activity of skeletal muscle fiber occurs in the granules (Lipoprotein granules, P e r ry, '52; mitochondria, Ch a pel and Per y, '53) as well as in the myofibrils (P e r r y, '51 and '54). P e r r y ('52) stated that the ATPase of the granules which accounted for $20-25 \%$ of the total ATPase activity of rabbit psoas muscles in the presence of magnesium at $\mathrm{pH} 7$, differs in several respects from myosin-ATPase which is localized in the isolated myoflbrils, but resembles more closely with the ATPase associated with mitochondria and the oxidative enzyme systems of cell. Pa d y k la et al $\left({ }^{\prime} 55,2\right)$ have doubted the presence 
of ATPase in the mitochondria of striated muscle and stated as follows: true ATPase of striated muscle occurs in the myofibrils and probably does not in the mitochondria or sarcoplasm; and either the ATPase activity of the mitochondria is too low to be tagged by the method which we have used or the conditions for the activity of this ATPase are not correct.

The present study of "Chiai" muscles indicates that ATPase activity appears to be exclusively associated with the mitochondria of sarcoplasm rather than with myofibrils, and furthermore that the activity is especially marked at the sites of the columnosomes.

On the other hand, several authors have reported that ATPase activity biochemically measured in liver cells, occurs mainly in the mitochondria and in the nuclei (Novikoff et al, 50 ; $\mathrm{Ki}$ ele $\mathrm{y}$ and $\mathrm{Kieley}$, '53; L a $\mathrm{dy}$ and $\mathrm{We} 11 \mathrm{man}$, '53). In rat liver, $\mathrm{Novik}$ of $\mathrm{f}$ et al ('50) found $70-75 \%$ of ATPase activity in the mitochondria, and $10-20 \%$ in the nuclei. More recently, N o vik of $f$ et al ('53) showed that mitochondrial fraction from rat liver homogenates possesses much higher activity for ATPase and succinoxidase than the other fractions. Ume m u ra ('54), by the use of DuBoisP otter's method, biochemically measured the ATPase activity of the "Chiai" muscle, and the lateral muscle and others. He reported that ATPase of the "Chiai" muscle is not activited by calcium ions, but exclusively by magnesium and manganese ions, and that its activity is far superior to that of the lateral muscle. The results reviewed here seem to be very helpful in confirming the authors' results. However, the present result indicate that the enzymatic histochemical activity of the "Chiai" muscle is much enhanced by calcium ions, but not increased so much by magnesium ions.

\section{Functional Significance of ATPase of "Chiai" Muscle Fibers}

Current studies on the biochemistry of muscle fibers have revealed that metabolism of carbohydrate consists of aerobic and anaerobic glycolysis: Energy obtained by both processes is utilized for muscular contraction and if needed, for other biological processes. In the anaerobic cycle, carbohydrate (glycogen, starch and glucose) is broken down to pyruvic acid through a series of phosphoric esters, and furthermore this is converted into lactic acid. However, under aerobic condition, pyruvic acid enters the tricarboxylic acid (TCA) cycle ( $\mathrm{Krebs}, 50)$, and finally is oxidized to carbon dioxide and water via the TCA cycle. It is known that glycolytic formation of 
lactic acid from glycogen under biological conditions is approximately about 57,000 calories for each 6-carbon unit of glycogen utilized. Accordingly, since glycolysis yields $3 \sim \mathrm{pH}$ bonds per 6 -carbon unit, it should be expected that complete oxidation of glycogen should yield about $36 \sim \mathrm{pH}$ bonds equivalent to some 720,000 calories ( $\mathrm{B}$ a l dw i n, '49). The total energy produced in this process is connected with energy-rich phosphate bond, attached to adenosine triphosphate. In the dephosphorylating process, on the contrary, only the terminal phosphate bond of ATP is released by ATPase and thus ATP is converted into ADP in the production of some 12,000 calories.

As already stated, the complete oxidation of glycogen yields 720,000 calories per 6-carbon unit. Because the "Chiai" muscle contains a great amount of glycogen in their sarcoplasm, it can easily be concluded that under aerobic glycolysis, glycogen will yield a large amount of energy in this muscle. With all these evidences the authors consider the "Chiai" muscle as being essentially an energy-rich organ; the excess free energy which is not used for muscle contraction, will be perhaps preserved, being connected with the phosphate bond attached to phosphocreatine.

In a previous paper ( $\mathrm{U}$ e $\mathrm{m}$ a $\mathrm{t} \mathrm{s} \mathrm{u},{ }^{\prime} 54$ ), the junior author reported on the great deal of accumulation of mitochondria in the "Chiai" muscle fiber and furthermore stressed their functional significance together with that of columnosomes: The mitochondria in this muscle are an intracellular enzymatic machinery which plays actively a most important part in respiration and the columnosomes are also enzymatically of particular significance due to their usual close contact with muscle columns. The abundant energy produced herein is supposed to be transferred via evergy-rich phosphate bond into myofibrils (actomyosin system) and utilized for durable contractile function. Accordingly, all the results obtained here will imply that in the "Chiai" muscle fiber, ATPase occupies an unique position as a catalyst in an energy-releasing process, although it is probable that in this muscle, dephosphorylating enzyme of phosphocreatine will be contained in a high concentration as such.

As already stated, the "Chiai" muscle contains a great amount of glycogen and accordingly, is indeed an energy-rich organ, and furthermore ATPase activity occurs very intensively in complete accordance with the situation of mitochondria as well as columnosomes in the sarcoplasm of this muscle. From the results reviewed it can be concluded that the high activity of ATPase is of much 
significance as an indicative of such abundant energy in an organ such as the "Chiai" muscle with a lasting; durable and tonical action.

\section{Relation to Electromyogramical and Mechanogramical Results}

An examination of electromyograms of the "Chiai" muscle fiber and the lateral ones reveals a definite difference from an electrophysiological aspect (I to, unpublished data). The "Chiai" muscle is composed of tonic muscle fiber; its action current consists of a characteristic wave form peculiar to tonic muscle. with spike discharges smaller in amplitude, lower in frequency, and accordingly, with longer intervals in comparison with those of the lateral muscle. On the contrary, from the electromyogramical expression, it can not be doubted that the lateral muscle pertains to the kinetic muscle which makes a phasic movement.

On the other hand, the mechanograms show that a twitch curve in the "Chiai" muscle is of much longer duration at isotonical stimulation than the lateral muscle (I o, unpublished data). This fact seems to indicate that the "Chiai" muscle has a durable and lasting function.

In a previous paper (U e mats u, '54) the junior author concluded that the "Chiai" muscle coritains high energy which serves for durable function and as a result of this, it may be able to strengthen a tension of the body sides of fishes and thus to exert an effective action upon static stability at great depth as well as upon the body movement in swimming. The conclusion can be proven from the energetics above mentioned, and also from the electrophysiological aspect.

\section{Summary and Conclusion}

The localization of ATPase and glycogen in the "Chiai" muscle in comparison with those of the lateral one was studied in relation to the distribution pattern of mitochondria.

In the "Chiai" muscle, ATPase activity appears exclusively in the sarcoplasm rather than in the myofibrils at $\mathrm{pH}$ 8.25. The activity is intensive, but of varying grades according to the length of incubation period. Its localization is in complete accordance with the site of mitochondria in the sarcoplasmic mantle as well as in the intercolumnar sarcoplasm. The junior author's columnosomes presented particularly much increased ATPase activity. 
The "Chiai" muscle contains a large amount of glycogen as energy source in the sarcoplasm. On the basis of this, energetics in the "Chiai" muscle was discussed in relation to ATPase activity and it led us to a conclusion that this muscle contains a large amount of energy which serves for durable action such as tension of the body sides of fish and for contractile action such as body movement in swimming. To support this last point, recent electrophysiological results related are discussed in this report.

\section{References}

A 11 e n, J.M. and J.J. SI at er, A chemical and histochemical study of enzymes dephosphorylating adenosine phosphate esters in the epididymis of normal, castrated, and testosterone propionate treated mice., Amer. J. Anat. 105, 1959, P. 117-140.

B a il e y, K., Myosin and adenosinetriphosphatase., Biochem. J. 36, 1942, P. 121-139.

- The proteins of skeletal muscle., Adv. Protein Chem. 1, 1944, P. 289-317.

B aldwin, E., Dynamic aspects of biochemistry., 1919, Cambridge University Press, New York.

Bodansky, O., Mechanism of inhibition of phosphatase activity by glycine., J. Biol. Chem. 165, 1946, P. 605-613.

C.h a p pe 11, J. B. and S. V. Perry, The respiratory and adenosine-triphosphatase activities of skeletal-muscle mitochondria., Biochem. J. 55, 1953, P. 586-595.

Engel hardt, W. A. and M.N. Li ubimova, Myosine and adenosine triphosphatase., Nature, 144, 1939, P. 668-669.

Eng e l ha rdt, V. A., Adenosinetriphosphatase properties of Myosin. Adv. Enzymol. 6, 1946, P. 147-191.

Gergely, J., Studies on myosin-adenosinetriphosphatase., J. Biol. Chem. 200, 1953, P. 543-550.

G i $1 \mathrm{~m}$ o u r, D., Myosin and adenylpyrophosphatase in insect muscle., J. Biol. Chem. 175, 1948, P. $477-478$.

Glick, D. and E.E. F ischer, The histochemical localization of adencsinetriphosphatase in plant and animal tissues., Science 102, 1945, P. 429-430.

Glick, D., Histochemical localization of adenosinetriphosphatase., Science 103, 1946, P. 599.

Green. I. and W.F.H.M. Mommaerts, Adenosinetriphosphatase systems of muscle. 1. An electrotitrimetric method of measurement., J. Biol. Chem. 202, 1953, P. 541-549.

Gomori, G., Histochemical specificity of phosphatases., Proc. Soc. Exp. Biol. Med. 70, 1949, P. 7-11.

- -, Alkaline phosphatase of cell nuclei., J. Lab. Clin. Med., 37, 1951, P. 526-531.

$\mathrm{H}$ a r m a n, J.W. and M. F e igels on, Studies on mitochondria. V. The relationship of structure and oxidative phosphorylation in mitochondria of heart muscle., Exp. Cell Res. 3/3, 1952, P. 509-525.

$\mathrm{Heppel,} \mathrm{L.A.} \mathrm{and} \mathrm{R.} \mathrm{J.} \mathrm{Hil} \mathrm{moe,} \mathrm{Mechanism} \mathrm{of} \mathrm{enzymatic} \mathrm{hydrolysis} \mathrm{of} \mathrm{adeno-}$ sinetriphosphate., J. Biol. Chem. 202, 1953, P. 217-226.

I t o, H., Unpublished data. 
J o hnson, P.L. and G. B evel ander, Glycogen and phosphatase in the developing hair., Anat. Rec. 95, 1946, P. 193-199.

J o h n s o n, M., K a y e, M. A. G., H e m s, R. and H. A. K r e b s, Enzymatic hydrolysis of adenosine phosphates by Cobra venom., Biochem. J. 54, 1953, P. 625-629.

$\mathrm{K}$ i elle $\mathrm{y}, \mathrm{W}$. W. and $\mathrm{O}$. Me yer h of, Studies on adenosinetriphosphatase of muscle. II. A new magnesium-activated adenosinetriphosphatase., J. Biol. Chem. 174, 1948, P. 38i-388. - Studies on adenosinetriphosphatase of muscle. II. A new magnesiumactivated adenosinetriphosphatase., J. Biol. Chem. 176, 1948, P. 591-601.

Kielley, W. W. and R. K. Kielley, A specific adenosinetriphosphatase of liver mitochondria., J. Biol. Chem. 200, 1953, P. 213-229.

Krebs, H. A., The tricarboxylic acid cycle., Charles C. Thomas, Springfield, I11., 1950 .

L a rdy, H. A, and H. We $11 \mathrm{~m}$ a n, The catalytic effect of 2,4-dinitrophenol on adenosinetriphosphate hydrolysis by cell particles and soluble enzymes, J. Biol. Chem. 201, 1953, P. 35i-370.

Lindberg, O. and L. Eruster, On the mechanism of phosphorslative energy transfer in mitochondria., Exp. Cell Res. 3 1, 1952, P. 209-239.

Lindeman, V.F., The rate of glycolysis and ATPase activity in the developing chick retina., Anat. Rec. 105, 1949, P. 103.

Lohmann, K., Über die enzymatische Aufspaltung der Kreatinphosphorsāure; zugleich ein Beitrag zum Chemismus der Muskelkontraktion., Biochem. Z. 271, 1934, S. 264-27T.

Ma engwyn-D aries, G. D., Friedenwald, J.S. and R.T. White, Histochemical studies of alkaline phosphatase in the tissues of the rat using frozen sections. II. Substrate specificity of enzymes hydrolyzing adenosinetriphosphate, muscle- and yeast adenylic acids and creatinephosphate at high pH; The histochemical demonstration of myosin ATPase., J. Cell. \& Comp. Physiol. 39, 1952. P. 395-434.

Mommaeris, W.F.H. .I. and I. Green, Adenosinetriphosphatase sistems of muscle. III. A survey of the adenosine-triphosphatase activity myosin. J. Biol. Chem. 208, 1954, P. 833-813.

Moog, F. and H.B. Steinbach, Notes on the possibility of a histochemical method for localizing adenosinetriphosphatase. Science 103, 1946, P. 144.

N e e dh a m, D. M., The adenosinetriphosphatase actirity of myosin preparations. Biochem. J. 36, 1942, P. 113-120.

Newman. W, Feigin, I., Wolf, A. and E. A. Kabat, Histochemical studies on tissue enzymes. IV. Distribution of some enzymes which liberate phosphate at $\mathbf{p H} 9.2$ as determined with various substrates and inhibitors; demonstration of three groups of enzymes., Amer. J. Path. 26, 1950, P. 257-291.

Corik of f, A.B., Podber, E. and J. Ryan, Iniracellular distribution of phosphatatase activity in rat liver., Fed. Proc. 9, 1950, P. 210.

Novikoff, A.B., Hecht, L., Podber, E. and J. Ryan, Phosphatases of rat liver. I. The dephosphorylation of adenosinetriphosphate., J. Biol. Chem. 194, 1952, P. 153-170.

Norikoff, A.B., Podber, E., Ry an, J. and E. Noe, Biochemical heterogeneity of cytoplasmic particles isolated from rat liver homogenate. J. Histoch. \& cytcch. 1, 1953, P. 2i-46. 
$\mathrm{Padykula}, \mathrm{H} . \mathrm{A}$. and E. Herman, Factors affecting the activity of adenosine triphosphatase and other phosphatase as measured by histochemical techniques, J. Histoch. \& Cytoch. 3, 1955, P. 161-169.

- The specificity of the histochemical method for adenosine triphosphatase., J. Histoch. \& Cytoch. 3, 1955, P. 170-195.

Perry, S.V., The adenosinetriphosphatase activity of myofibrils isolated from skeletal muscle. Biochem. J. 48, 1951, P. 257-265.

- The adenosinetriphosphatase activity of lipoprotein granules isolated from skeletal muscles. Biochem. Biophys. Acta, 8, 1952, P. 499-509.

- The intracellular localization of adenosinetriphosphate metabolism in skeletal muscle. Proc. Roy. Soc. London B. 142, 1954, P. 175-177.

Polis, B. D. and O. Me ye $r$ hof, Studies on adenosinetriphosphatase in muscle. I. Concentration of the enzyme on myosin. J. Biol. Chem. 169, 1947, P. 389-402.

Price and Cori, 1946, (cited from Yos hi kaw a, H., ATP (Japanese) in Medical Science (Japanese) 4, 1952, P. 2-8).

Sing er, T.P. and E.S.G. B ar ron, Effect of sulfhydryl reagents on adenosinetriphosphatase activity of myosin. Proc. Soc. Exp. Biol. Med. 56, 1944, P. 120-124.

$\mathrm{St}$ e i n b a ch, H. B. and F. Moog, Localization of adenylpyrophosphatase in cytoplasmic granules. J. Cell. \& Comp. Physiol. 26, 1945, P. 175-183.

Szent-Györgyi. A., Chemistry of muscular contraction, 1951, 2nd edition, Academic Press, New York N.Y.

W a chste in, M. and E. Meise l, Histochemistry of hepatic phosphatases at a physiologic $\mathrm{pH}$ with special reference to the demonstration of bile canaliculi., Amer. J. Clinic. Path. 27, 1957, P. 13-23.

Uematsu, H., Comparative-histological studies on muscle fibers of the fish. (Japanese), Arch. Hist. Jap. 3, 1951, P. 1-10.

- Studies on the mitochondria of the "Chiai" muscle (red muscle) of the fish., Okajimas Fol. anat. jap. 26, 1954, P. 51-65.

, Functional significance of the "Chiai" muscle fibers observed from the histological view point. (Japanese),, Kaibo. Z. 30, 1955, P. 48.

, Researches on the adenosine triphosphatase observed from the histochemical view point. 1. Adenosine triphosphatases in the "Chiai" muscle of the fish. (Japanese), Kaibo. Z., 31, 1956, P. 93-94.

- On the histochemical demonstration and identification of the adenosine triphosphatase activity in the tissue section, with special reference to the biological significance of this enzyme. (Symposium), (Japanese), Kaibo. $Z$. 32, 1957, P. 670-671.

, Histochemical demonstration of the alkaline phosphatase activity in the tissue section. 1) Preparations incubated with sodium phenylphosphate as a substrate. (Japanese), Kaibo. Z. 34, 1959, P. 83.

Ume mura, K., ATPase in the "Chiai" muscle of the fish. (Japanese), Seikagaku, 26, 1954, P. 156-157. 


\section{Explanations of Plate}

All figures illustrated are photomicrographs of tissue sections of two kinds of muscle fiber in Carassius auratus [LINNÉ].

Figure 1. Cross section of the "Chiai" muscle fiber.

The muscle fiber contains short band-shaped myofibrils (muscle columns) which wind and fuse to form networks: It indicates the muscle fiber of the reticular type according to the junior author's classification (U e m a t s u.'51). Mitochondria are observed in large amounts in the sarcoplasmic mantle found between the muscle column field and sarcolemm; the junior author's columnosomes (belonging to mitochondria) are found bilaterally in contact with both margins of muscle columns. Regaud's fluid; Heidenhain's iron hematoxylin stain; $\times 4,000$.

Figures 2 and 3. ATPase activity of cross section of the "Chiai" muscle fiber.

The sarcoplasmic mantle shows much higher activity as compared with the intercolumnar sarcoplasm; ATPase activity occurs in accordance with the situation of mitochondria as well as columnosomes. 12 hours' incubation; pH 8.25 ; Fig. 2, $\times 200$; Fig. $3, \times 800$.

Figure 4. ATPase activity of longitudinal section of the "Chiai" muscle fiber.

ATPase activity occurs as bilateral fringes in accordance with the localization of mitochondria and columnosomes of the sarcoplasmic mantle. $\times 200$.

Figure 5. ATPase activity of cross section of the lateral muscle fiber.

In this muscle fiber, sarcoplasm indicates a far less activity than in the "Chiai" muscle fiber. $\times 200$.

Figure 6. Glycogen of cross section of the "Chiai" muscle fiber.

Glycogen is much richer in amount than in the lateral muscle fiber. It appears packed in the sarcoplasmic mantle; in many muscle fibers, glycogen is found to be displaced by the fixative. 
Plate

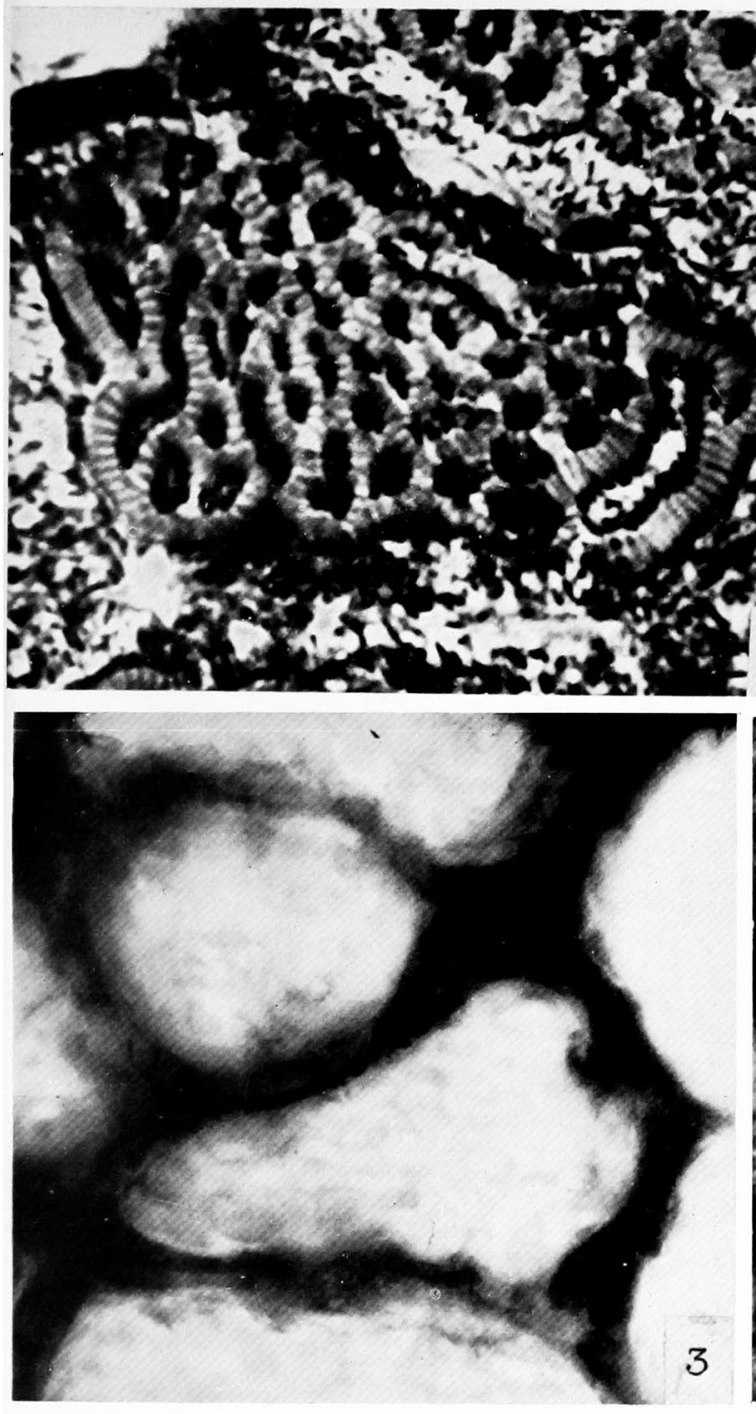

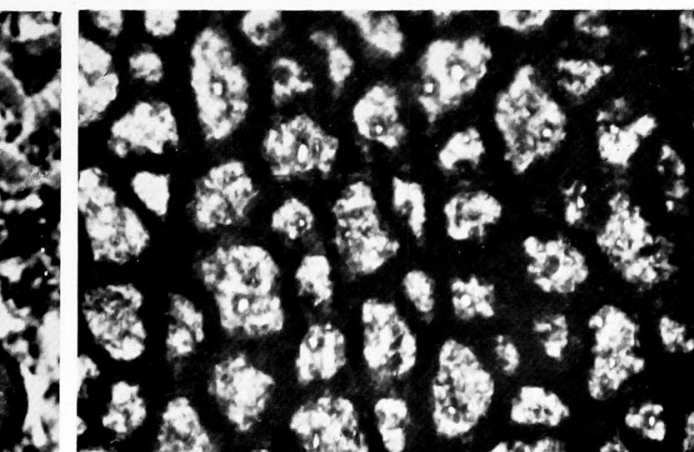

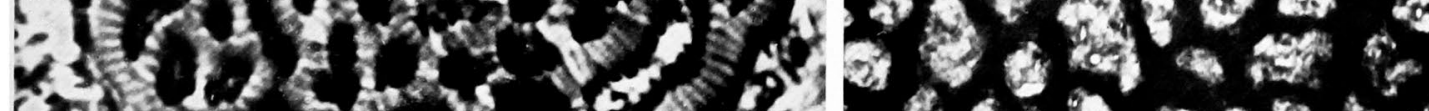

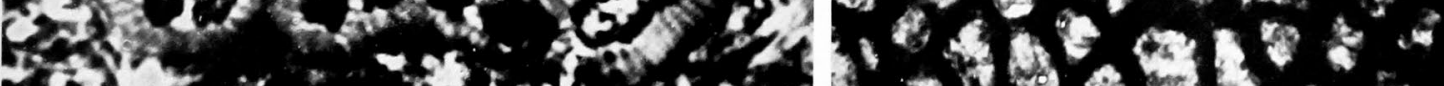

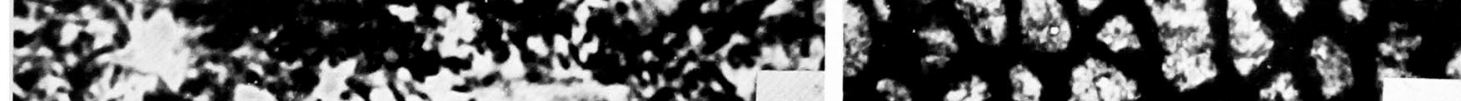

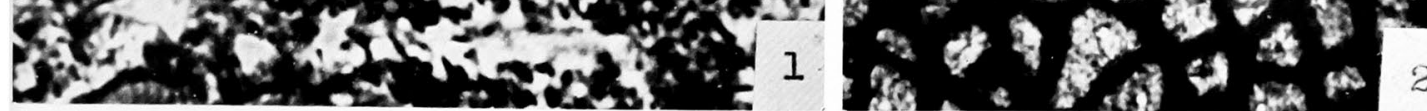
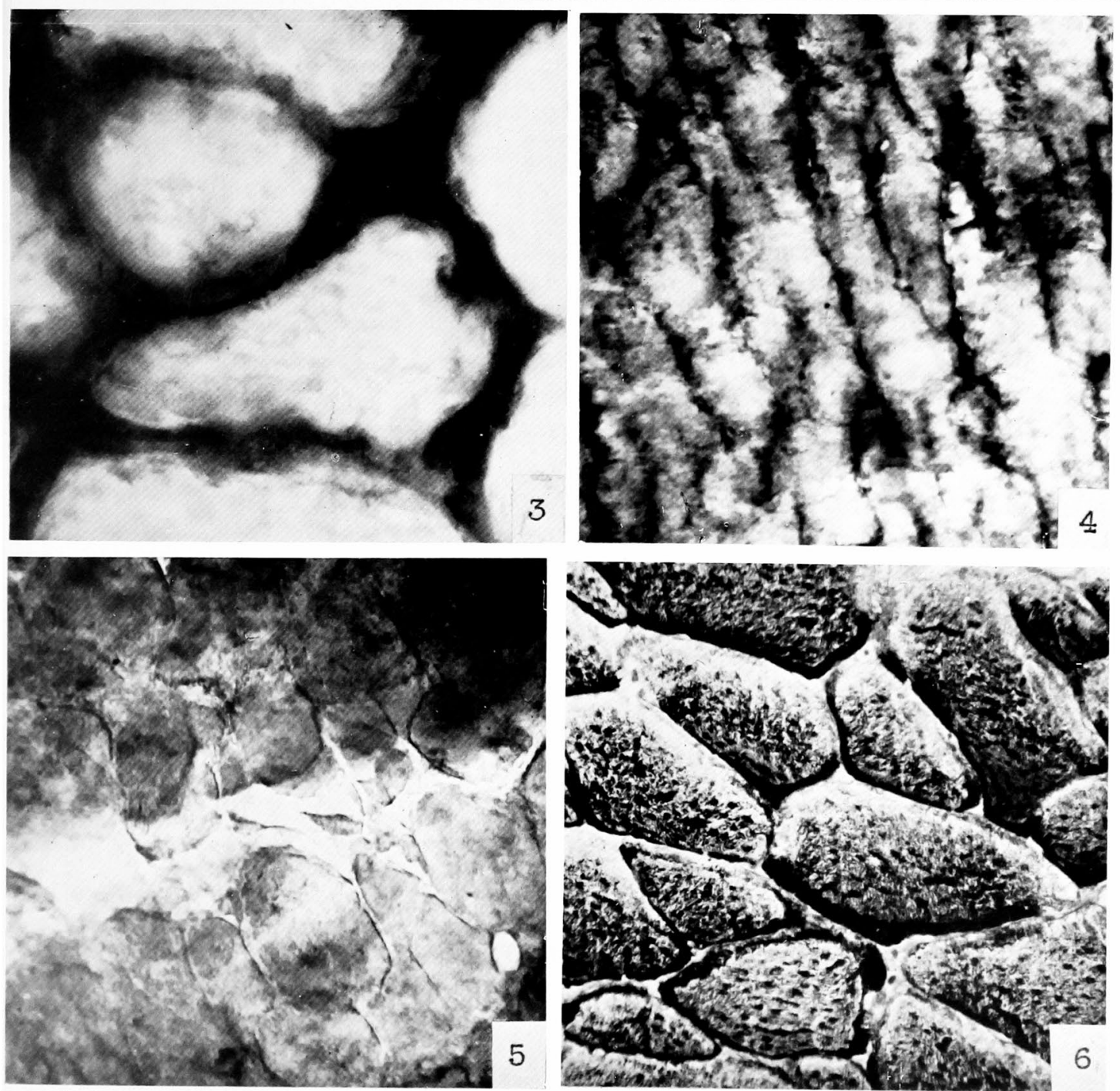